\title{
Oreochromis niloticus 'da Bakırın Karaciğer, Solungaç, Böbrek Ve Kas Dokularında G6PD Aktivitesine Etkisi I*I
}

\author{
Tüzün AYTEKİN ${ }^{1} \quad$ Ferit KARGIN ${ }^{2}$ \\ ${ }^{l}$ Cukurova Üniversitesi, İmamoğlu MYO, İmamoğlu/Adana. (10: https://orcid.org/0000-0003-2666-0798 \\ ${ }^{2}$ Çukurova Üniversitesi, Fen Edebiyat Fakültesi, Biyoloji Bölümü, Sarıçam/Adana. $\mathbb{D}$ : https://orcid.org/0000-0003-4315-5689
}

Atıf yapmak için: Aytekin, T. \& Kargın, F. (2019). Oreochromis niloticus 'da Bakırın Karaciğer, Solungaç, Böbrek Ve Kas Dokularında G6PD Aktivitesine Etkisi. Anadolu Çev. ve Hay. Dergisi, 4(2), 60-63.

How to cite: Aytekin, T. \& Kargın, F. (2019). Effect of Copper on G6PD Activity in the Liver, Gill, Kidney and Muscle Tissues of Oreochromis niloticus. Anatolian Env. and Anim. Sciences, 4(2), 60-63.

Öz: Bu çalışmada bakır'ın Oreochromis niloticus'da glukoz-6-fosfat dehidrojenaz (G6PD) aktivitesi üzerine etkileri araştırılmıştır. Balıklar 0.6, 3.0 ve $6.0 \mathrm{mg} / \mathrm{L} \mathrm{Cu}$ derişimlerinin etkisine 15 ve 3014 günlük sürelerle bırakılarak karaciğer, solungaç, böbrek ve kas dokularında glukoz-6-fosfat dehidrojenaz (G6PD) aktiviteleri belirlenmiştir. Bakırın farklı derişimlerinin etkisine bırakılan O. niloticus'un karaciğer, böbrek, solungaç ve kas dokularında glukoz-6-fosfat dehidrojenaz (G6PD) enzim aktivitesi kontrol değerleriyle ile karşılaştırıldığında önemli değişiklikler belirlenmiştir. Bakırın denenen tüm derişimleri karaciğer ve böbrek dokusunda glukoz-6-fosfat dehidrojenaz (G6PD) aktivitesinin azalmasına, solungaç dokusunda ise bir artışa neden olmuştur.

\section{Effect of Copper on G6PD Activity in the Liver, Gill, Kidney and Muscle Tissues of Oreochromis niloticus}

Abstract: In this study, the effects of copper on the glukoz-6-fosfat dehidrojenaz (G6PD) activity in Oreochromis niloticus were investigated. Fishes were exposed to $0.6,3.0$ and $6.0 \mathrm{mg} / \mathrm{L} \mathrm{Cu}$ for 15 and 30 days to determine glukoz-6-fosfat dehidrojenaz (G6PD) activities in liver, gill, kidney and muscle tissues. The significant changes were determined in glukoz-6-fosfat dehydrogenase (G6PD) activities in liver, gill, kidney and muscle tissues of $O$. niloticus exposed to copper compared to controls. In all the concentrations tested, copper caused a decrease in glucose-6-phosphate dehydrogenase (G6PD) activity in the liver and kidney while it caused an increase in the gill. 


\section{GíRIŞ}

Son yüz yılda hızlı nüfus artışına bağlı olarak artan çevre kirliliği, yaşam kaynaklarının daha fazla kirlenmesine neden olmuş ve sonuçta ekosistemin bozulması giderek çok daha ciddi bir durum almıştır. Ağır metaller akuatik ortamda doğal olarak çok az bulunurlar. Bununla birlikte endüstride yoğun bir şekilde kullanımı nedeniyle ortama girmekte, yoğunlaşmakta ve diğer formlara dönüşerek su organizmaları üzerine toksik etki yapmaktadırlar.

Bakır madencilikte, elektrik, boya ve cam sanayinde, tarımda ve kültür balıkçılığında, su bitkilerini kontrol altına almada kullanılmaktadır. Su ortamında artan bakır derişimleri, balıklarda bu metalin birikiminin giderek artmasına neden olmaktadır. Bakır birikiminin balıklarda kan parametreleri (Couture \& Kumar, 2003), enzim aktiviteleri (Lopes vd., 2001) ve üremeleri üzerine (Roch \& McCarter, 1984) önemli etkileri vardır.

Ağır metal iyonlarının bitkisel, mikrobiyal ve hayvansal enzimler üzerine olumsuz etkileri vardır (Isamah vd., 2000; Ali vd., 2003). Su organizmalarında ağır metaller enzimlerin fonksiyonel gruplarına (sülfidril, karboksil, imidazol) bağlanarak veya enzimdeki faydalı bir metalin yerini alarak enzim aktivitelerini değiştirebilmektedir (Viarengo, 1985; Lionetto vd., 1998).

Antioksidan enzimler hücre homeostasisinin sürdürülmesinde önemli rol oynamaktadırlar. Birçok omurgalı ve omurgası hayvanda oksiradikallerin detoksifikasyonunda antioksidan enzimlerin önemli bir rol oynadığı belirtilmiştir (Regoli \& Principato, 1995). Antioksidan enzimler, oksidatif stresi göstermede iyi bir moleküler indikatördürler ve genelde metallerin etkisine bırakılan organizmalarda bir tepki olarak oluşmaktadırlar. Glukoz-6-fosfat dehidrojenaz (G6PD), azalan NADPH'nn sağlanmasında anahtar bir enzimdir ve kirleticilerin etkisinde su organizmalarının karaciğer ve solungaçlarında arttığ belirlenmiştir (Sridevi vd., 1998). Glukoz-6- fosfat dehidrojenazın aktivitesindeki artışın oksidatif stres altındaki organizmalara ilave enerjiyi sağlamak amacıyla olduğu saptanmıştır.

$\mathrm{Bu}$ araştırmada, bakırın $O$. niloticus'un karaciğer, solungaç, böbrek ve kas dokularında glukoz-6-fosfat dehidrojenaz (G6PD) enzim aktivitesi üzerine etkisinin belirlenmesi amaçlanmıştır.

\section{MATERYAL ve METOT}

Araştırma materyali olarak kullanılan $O$. niloticus örnekleri Ç.Ü. Su Ürünleri Fakültesi Yetiştirme havuzlarından alınarak $40 \times 120 \times 40 \mathrm{~cm}$ boyutlarındaki akvaryumlarda $25 \pm 1{ }^{\circ} \mathrm{C}$ de bir ay süre ile laboratuvar koşullarına adaptasyonları sağlanmıştır. $\mathrm{Bu}$ süre içerisinde balıklar $11.8 \pm 0.7 \mathrm{~cm}$ boy ve $25.5 \pm 5.0 \mathrm{~g}$ ağırlı̆ga ulaşmışlardır.
Deneylerde 40X120X40 cm. boyutlarinda olan ve her birinin içerisinde 12 balık bulunan 4 cam akvaryum kullanılmıştır. Bu akvaryumlardan üçüne 120'şer litre 0.6, 3.0 ve $6.0 \mathrm{mg} / \mathrm{L} \mathrm{Cu}$ çözeltileri, dördüncü akvaryum kontrol olarak kullanılmıştır. Deneyler üç tekrarlı olarak yürütülmüştür ve her tekrarda iki balık kullanılmıştır.

Deney ortamında bakır derişimlerinde süreye bağlı olarak değişimler olabileceği dikkate alınarak deney süresince akvaryum çözeltileri iki günde bir değiştirilmiştir. Deneylerde kullanılan bakır klorür $\left(\mathrm{CuCl}_{2} .2 \mathrm{H}_{2} \mathrm{O}\right.$, Merck) çözeltilerinin akvaryumda homojen dağılması ve çökelmeyi önlemek için trisodyum sitratla $\left(\mathrm{C}_{6} \mathrm{H}_{5} \mathrm{Na}_{3} \mathrm{O}_{7} .2 \mathrm{H}_{2} \mathrm{O}\right.$ Merck) çözeltisi kullanılmıştır.

Belirtilen süreler sonunda her akvaryumdan 6 balık çıkarılarak üzerlerinde bulunan su damlacıkları kurutma kâğıdı ile alınarak karaciğer, böbrek, kas ve solungaç dokuları disekte edilmiştir. Dokular glukoz-6-fosfat dehidrojenaz (G6PD) enzim analizleri için \%0.59'luk $\mathrm{NaCl}$ damlatıldıktan sonra $-80^{\circ} \mathrm{C}^{\prime}$ lik derin dondurucuda saklanmıştır. Derin dondurucudan çıkartılan dokular üzerine 1/10 oranında $0.25 \mathrm{M}$ sükroz (pH:7.4) eklenerek buz içerisinde teflon homojenizatörde $5 \mathrm{dk}$ süreyle homojenize edildikten sonra $+4^{\circ} \mathrm{C}^{\prime} \mathrm{de} \quad 10.000$ rpm'de 30 dakika santrifüjlendikten sonra süpernatantlarda G6PD enzim aktiviteleri belirlenmiştir.

Glukoz-6-Fosfat Dehidrojenaz (G6PD) Yöntemi: Glukoz-6-fosfattan 6-fosfoglukanolaktan oluşması sırasında indirgenen NADP miktarı bu tepkimeyi katalizleyen G6PD enziminin aktivitesi ile doğru orantılıdır. Enzim aktivitesinin ölçülmesi tepkime sırasında oluşan NADPH'ın $340 \mathrm{~nm}$ dalga boyunda birim zamanda verdiği absorbans farkının saptanması esasına dayanır (Beutler, 1975).

Ístatiksel Analiz: Deneylerden elde edilen verilerin istatistik analizleri SPSS 10.0 bilgisayar paket program kullanılarak "Regresyon Analizi" ve "Student Newman Keul's (SNK)" testleri uygulanarak yapılmıştır.

\section{BULGULAR}

O. niloticus' da belirli bir sürede dokularda G6PD aktivitesi üzerine bakırın derişime bağlı etkileri Çizelge 1 ve 2' de verilmiştir. 15. günde kas dokusu hariç diğer dokularda denenen yüksek ortam derişimlerinde G6PD aktivitesinin değiştiği gözlenmiştir. Karaciğer ve böbrek G6PD aktivitesi azalırken solungaç dokusu G6PD aktivitesinin arttığ belirlenmiştir (Çizelge 1, SNK; $\mathrm{P}<0.05$ ). 30. günde denenen yüksek ortam derişimlerinde karaciğer ve böbrek dokusu G6PD aktivitesi azalırken solungaç dokusu G6PD aktivitesinin ise arttığ saptanmıştır (Çizelge 2, SNK; $\mathrm{P}<0.05$ ).

Bakır derişimlerinin süreye bağlı olarak $O$. niloticus'un farklı dokularında G6PD aktivitelerine etkileri Şekil 1. A, B, C ve D' de verilmiştir. 30. gün en yüksek bakır ortam derişiminde karaciğer ve böbrek dokusu G6PD 
aktivitesi sırasıyla $\% 41$ ve $\% 26$ oranında azalırken, solungaç dokusu G6PD aktivitesi ise \%49 oranında arttığı belirlenmiştir (Şekil 1B ve D). Kas dokusunda herhangi bir değişimin olmadığı saptanmıştır.

Tablo 1. O. niloticus' da 15 günlük süre sonunda bakırın doku ve organlarda G6PD aktivitesi (U/mg protein) üzerine etkisi.

\begin{tabular}{lllll}
\hline \multirow{2}{*}{ Derişim } & \multicolumn{4}{c}{ Dokular } \\
\cline { 2 - 5 } & $\mathbf{K a r a c i g ̆ e r *}$ & $\mathbf{B o ̈ b r e k *}$ & Kas* & Solungaç* \\
& $\overline{\mathrm{X}} \pm \mathrm{S} \overline{\mathrm{X}}$ & $\overline{\mathrm{X}} \pm \mathrm{S} \overline{\mathrm{X}}$ & $\overline{\mathrm{X}} \pm \mathrm{S} \overline{\mathrm{X}}$ & $\overline{\mathrm{X}} \pm \mathrm{S} \overline{\mathrm{X}}$ \\
\hline Kontrol & $0.202 \pm 0.001 \mathbf{x}$ & $0.048 \pm 0.005 \mathbf{x}$ & $0.0017 \pm 0.0002 \mathbf{x}$ & $0.043 \pm 0.002 \mathbf{x}$ \\
$0,6 \mathrm{ppm} \mathrm{Cu}$ & $0.183 \pm 0.010 \mathbf{x y}$ & $0.038 \pm 0.004 \mathbf{x y}$ & $0.0021 \pm 0.0002 \mathbf{x}$ & $0.052 \pm 0.002 \mathbf{y}$ \\
$3,0 \mathrm{ppm} \mathrm{Cu}$ & $0.166 \pm 0.005 \mathbf{y}$ & $0.033 \pm 0.005 \mathbf{y}$ & $0.0021 \pm 0.0002 \mathbf{x}$ & $0.052 \pm 0.002 \mathbf{y}$ \\
$6,0 \mathrm{ppm} \mathrm{Cu}$ & $0.162 \pm 0.004 \mathbf{y}$ & $0.034 \pm 0.002 \mathbf{y}$ & $0.0022 \pm 0.0002 \mathbf{x}$ & $0.052 \pm 0.003 \mathbf{y}$ \\
\hline Değerler aritmetik ortalama \pm standart hata olarak verilmisțir. & &
\end{tabular}

Degerler aritmetik ortalama \pm standart hata olarak verilmiststir.
$*:$ Aynn sütunda farklı harflerle gösterilen veriler arasinda $\mathrm{P}<0.05$ düzeyinde ayırım vardır.

Tablo 2. O. niloticus' da 30 günlük süre sonunda bakırın doku ve organlarda G6PD aktivitesi (U/mg protein) üzerine etkisi.

\begin{tabular}{|c|c|c|c|c|}
\hline \multirow{3}{*}{ Derişim } & \multicolumn{4}{|c|}{ Dokular } \\
\hline & Karaciğer* & Böbrek* & Kas* & Solungaç* \\
\hline & $\bar{X} \pm S \bar{x}$ & $\bar{X} \pm S \bar{x}$ & $\bar{X} \pm S \bar{x}$ & $\bar{X} \pm S \bar{x}$ \\
\hline Kontrol & $0.239 \pm 0.006 \mathbf{x}$ & $0.046 \pm 0.005 \times$ & $0.0027 \pm 0.0002 \mathbf{x}$ & $0.047 \pm 0.004 \mathbf{x}$ \\
\hline $0,6 \mathrm{ppm} \mathrm{Cu}$ & $0.211 \pm 0.006 \mathbf{x y}$ & $0.038 \pm 0.003 \mathbf{x y}$ & $0.0026 \pm 0.0002 \mathbf{x}$ & $0.053 \pm 0.003 \mathrm{xy}$ \\
\hline $3,0 \mathrm{ppm} \mathrm{Cu}$ & $0.190 \pm 0.004 \mathbf{y}$ & $0.036 \pm 0.002 \mathbf{y}$ & $0.0033 \pm 0.0001 \mathbf{x}$ & $0.066 \pm 0.004 \mathrm{yz}$ \\
\hline $6,0 \mathrm{ppm} \mathrm{Cu}$ & $0.141 \pm 0.015 \mathrm{z}$ & $0.034 \pm 0.003 \mathbf{y}$ & $0.0033 \pm 0.0002 \mathbf{x}$ & $0.070 \pm 0.005 \mathrm{z}$ \\
\hline
\end{tabular}

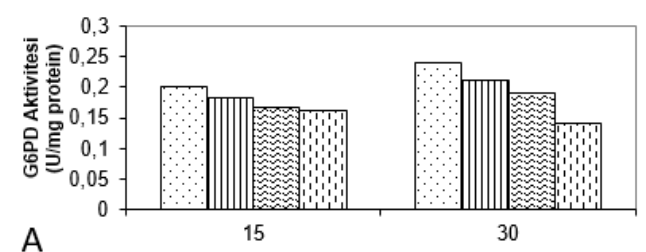

A

15

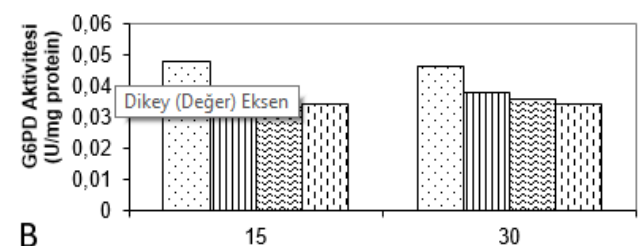

15

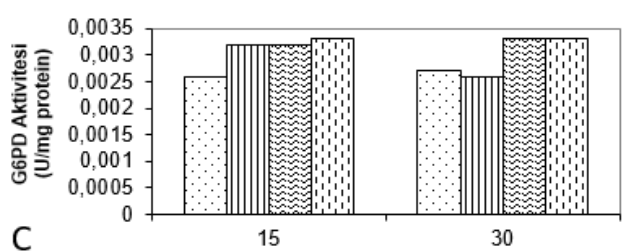

15

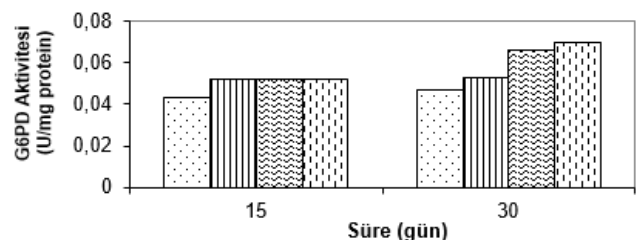

D

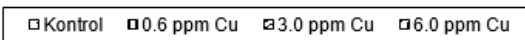

Şekil 1. O. niloticus' un karaciğer (A), böbrek (B), kas (C) ve solungaç (D) dokusunda G6PD aktivitesi üzerine bakır ortam derişimleri ve sürenin etkisi.

\section{TARTIŞMA ve SONUÇ}

$\mathrm{Bu}$ araştırmada $O$. niloticus'da $6.0 \mathrm{ppm} \mathrm{Cu}$ ortam derişiminde deneylerin sona erdirildiği 30 günlük süre içerisinde ölüm gözlenmemiştir. Ağır metallerin balıklarda yüksek derişimlerde mortaliteye neden olmamaları çeşitli akklimasyon ve detoksifikasyon mekanizmalarının iyi olmasından kaynaklanmaktadır.

Akuatik hayvanlarda savunma sistemleri oksiradikal forumlara karşı gelişmektedirler. Farklı metallerin etkisinde oksiradikallerin düzeyi artabilmektedir. Oksiradikallerin varlığ 1 antioksidan enzimlerin oluşumuna neden olmakta ve metallerin indüklediği oksidatif stres esnasında artarak metallerin olumsuz etkilerine karşı organizmayı korumaktadırlar. Kirleticilere karşı organizmalardaki antioksidan tepkiler doku, derişim ve süreye bağlı olarak değişmektedir (Hansen vd., 2006).

Glukoz-6-Fosfat Dehidrojenaz (G6PD) önemli bir antioksidan enzim olup pentozun çevrilmesinde önemli bir bileşendir. G6PD, NADP nükleotidinin indirgenmesinde anahtar bir enzimdir. Oksidatif stres hücre içi glutatyonu tüketir, bunun onarılması glutatyon redüktaz tarafından geçekleşir ki burada kullanılan NADP G6PD tarafından sağlanır (Venugopal vd., 1997). G6PD, NADP'de koenzim olarak kullanılır ve lipid sentezi için kullanılan NADPH'nin oluşumunu sağlar (Levesque vd., 2002).

Bakırın etkisine 15 ve 30 sürelerle birakılan $O$. niloticus'un karaciğer ve böbreklerinde G6PD aktivitesi tüm derişimlerde azalırken solungaç dokusunda ise artış göstermiştir. 30.gün sonunda Cu'ın etkisinde $6.0 \mathrm{ppm}$ ortam derişiminde karaciğerde G6PD aktivitesi \%41, böbrekte \%26 azalırken, solungaç dokusunda ise \%49 oranında arttığı saptanmıştır. Cu'ın etkisinde karaciğer ve böbrekte G6PD aktivitesindeki azalma, Cu'ın -SH guruplarına bağlanması ve oksidatif stresten kaynaklanabilir. Kas dokusunda denenen tüm bakır ortam derişimlerinin etkisinde ve sürelerde G6PD aktivitesi herhangi bir değişim göstermediği belirlenmiştir. Kirlenmiş nehirlerden alınan $O$. niloticus'un karaciğerinde G6PD aktivitesinin azaldığı belirtilmiştir (Bainy vd., 1996). Sastry \& Agrawal (1979) civa klorürün etkisine 96 saat ve 30 gün süreyle bıraktıkları $C$. punctatus'un böbrek ve ovaryumunda G6PD aktivitesinin azaldığını ve bu azalmanın mitokondriyal hasar nedeniyle hücrenin metabolizmasındaki bozukluklara bağlanabileceğini belirtmişlerdir.

\section{TEŞEKKÜR}

$\mathrm{Bu}$ çalışma Çukurova Üniversitesi Bilimsel Araştırma Projeleri birimi (BAP) tarafından desteklenmiştir (Proje No: FEF2003D12).

\section{KAYNAKLAR}

Ali, M.B., Vajpayee, P., Tripathi, R.D., Rai, U.N., Singh, S.N. \& Singh, S.P. (2003). Phytoremediation of lead, nickel, and copper by Salix acmophylla Boiss: role of antioxidant enzymes and antioxidant 
substances. Bulletin of Environmental Contamination and Toxicology, 70, 462-469.

Bainy, A.C.D., Saito, E., Carvalho, P.S.M. \& Junqueira, V.B.C. (1996). Oxidative stres in gill, erythrocytes, liver and kidney of Nile tilapia (Oreochromis niloticus) from a polluted sites. Aquatic Toxicology, 34, 151-162.

Beutler, E. (1975). Red cell metabolism. Grune and Starton, $2^{\text {nd }}$ ed., New York.

Couture, P. \& Kumar, P.R. (2003). Impairment of metabolic capacities in copper and cadmium contaminated wild yellow perch (Perca flavescens). Aquatic Toxicology, 64, 107-120.

Hansen, B.H., Romma, S., Garmo, A., Olsvik, P.A. \& Andersen, R.A. (2006). Antioxidative stres proteins and their gene expression in Brown trout (Salmo trutta) from three rivers with different heavy metal levels. Comparative Biochemistry and Physiology Part C, 143, 263-274.

Isamah, G.K., Asagba, S.O. \& Coker, H.A.B. (2000). Comparative evaluation of the levels of some antioxidant enzymes and lipid peroxidation in different fish species in two rivers in the Western Niger Delta. Bulletin of Environmental Contamination and Toxicology, 65, 351-356.

Levesque, H.M., Moon, T.W., Campbell, P.G.C. \& Hontela, A. (2002). Seasonal variation in carbohydrate and lipid metabolism of Yellow perch (Perca flavescens) chronically exposed to metals in the fiels. Aquatic Toxicology, 60, 257-267.

Lionetto, M.G., Maffia, M., Cappello, M.S., Giordano, M.E., Storelli, C. \& Schettino, T. (1998). Effect of cadmium on carbonic anhydrase and $\mathrm{Na}^{+}-\mathrm{K}^{+}-$ ATPase in eel, Anguilla anguilla, intestine and gills. Comparative Biochemistry and Physiology Part A, 120, 89-91.

Lopes, P.A., Pinheiro, T., Santos, M.C., Mathias, M.L., Collares-Pereira, M.J. \& Viegas-Crespo, A.M. (2001). Response of antioxidant enzymes in freshwater fish populations (Leuciscus alburnoides complex) to inorganic pollutants exposure. The Science of the Total Environment, 280, 153-163.
Regoli, F. \& Principato, G., (1995). Glutathione, glutathione-dependent and antioxidant enzymes in Mussel, Mytilus galloprovinciallis, exposed to metals under field and laboratory conditioons: implications for the use of biochemical biomarkers. Aquatic Toxicology, 31, 143-164.

Roch, M. \& McCarter, J.A. (1984). Hepatic metallothionein production and resistance to heavy metals by Rainbow trout (Salmo gairdneri)-I. exposed to an artifical mixture of zinc, copper and cadmium. Comparative Biochemistry and Physiology, 77, 71-75.

Sridevi, B., Reddy, K.V. \& Reddy, S.L.N. (1998). Effect of trivalent and hexavalent chromium on antioxidant enzyme activities and lipid peroxidation in a freshwater field Crab, Barytelphusa guerini. Bulletin Environmental Contamination and Toxicology, 61, 384-390.

Sastry, K.V. \& Agrawal, M.K. (1979). Mercuric chloride induced enxymological changes in kidney and ovary of a Teleost fish, Channa punctatus. Bulletion Environmental Contamination and Toxicology, 22, 38-43.

Venugopal, N.B.R.K., Ramesh, T.V.D.D., Reddy, D.S. \& Reddy, S.L.N. (1997). Effect of cadmium on antioxidant enzyme activities and lipid peroxidataion in a freshwater field Crab, Barytelphusa guerini. Bulletin of Environmental Contamination and Toxicology, 59, 132-138.

Viarengo, A. (1985). Biochemical effects of trace metals. Marine Pollution Bulletin, 16(4), 153-158.

\author{
*Corresponding author's: \\ Tüzün AYTEKIN \\ Çukurova Üniversitesi, İmamoğlu MYO, İmamoğlu/Adana, Türkiye \\ \e-mail: tuzunay@cu.edu.tr \\ ORCID: https://orcid.org/0000-0003-2666-0798
}

